\title{
Economic Analysis of Wind Turbine Installation in Taiwan
}

\author{
Jeeng-Min Ling and Kunkerati Lublertlop \\ Department of Electrical Engineering, Southern Taiwan University of Science and Technology, Tainan 710, Taiwan \\ Correspondence should be addressed to Jeeng-Min Ling; jmling@mail.stust.edu.tw
}

Received 30 September 2014; Accepted 2 December 2014

Academic Editor: Mo Li

Copyright ( 2015 J.-M. Ling and K. Lublertlop. This is an open access article distributed under the Creative Commons Attribution License, which permits unrestricted use, distribution, and reproduction in any medium, provided the original work is properly cited.

\begin{abstract}
The wind speed characteristics are analyzed statistically based on a long-term hourly data record to evaluate the proper wind energy potential. The annual average wind speed and wind power density are investigated and compared by some significant indices, wind energy output and capacity factor, to show the variations of proper wind turbine specifications of installation in different locations of Taiwan. The minimum cost of wind energy is used to assess the economical feasibility for turbine installation in Taiwan. Great variations occur in the simulation results in both of the cost of energy and capacity factor. The detailed statistical analysis should be conducted to ensure the successful operation after wind turbine installations.
\end{abstract}

\section{Introduction}

The demand for energy and particularly for electricity is growing rapidly in the country of rapid economic growth. Taiwan has no nature reserves, but electricity mainly relied on conventional fossil fuel. The development of electricity capacity from renewable energy in Taiwan is vital. In this aspect, wind power plays a major role in the enhancement of renewable energy before a sharp increasing in the photovoltaic energy after year 2020 [1]. With abundant wind resources along the west coast of Taiwan and some offshore islands, the Asian monsoon, tropical cyclones during the summer season and the northeast trade winds during the winter season, induces high winds speed in many regions. Taiwan has superior advantages to develop wind energy geographically.

Many studies related to the study of wind characteristics and wind power potentials have been conducted worldwide recently [2-6]. Belu and Koracin studied the wind characteristic in western Nevada, USA, in which the wind speed at different tower heights is estimated using the standard power extrapolation equation and consequently the power law exponent values are analyzed for different time periods and locations [7]. The empirical and graphical methods were used to analyze the wind power density at the heights of 10,30 , and $60 \mathrm{~m}$, respectively [8]. Two statistical methods, meteorological and Weibull, were presented to evaluate the wind speed characteristic and the wind power potential at an open area of 17 synoptic sites distributed throughout the territory of Tunisia [9].

Many researchers have proposed different economic methods to assess installation of wind turbine. Fingersh et al. presented a simple payback period method [10]. The simple payback period is the number of years which will be taken to recover the initial capital cost for installation of a new wind turbine generator (WTG). An important issue of this model is assumed by the fact that WTG will produce the same amount of electricity each year and attain constant revenue stream. However, the discount rate and the lifetime of the project are not considered. The cost model of wind energy is defined as the unit cost to produce energy from the WTG system. The numbers of lifetime of project and discount rate are included when annual cost is evaluated. Schmidt constructed expressions for computing component costs of wind turbine [11].

This paper proposes a procedure based on the detailed economical model including wind turbine components cost, the annual operation, and maintenance cost of wind turbine to get the minimum cost of wind energy. The minimum cost of wind energy was used to assess the feasibility of installed wind turbine at 24 locations in Taiwan. The wind energy output and capacity factor of twenty commercial wind 
turbines in terms of different designed hub height were also investigated.

\section{The Mathematical Models for Wind Energy}

Using estimation of regional wind resources, one can estimate the electrical producing potential of wind energy. This wind energy resource atlas identifies the wind characteristics and distribution of the wind resource. An important parameter in the characterization of the wind resource is the variation of horizontal wind speed which is expected to be zero at the earth's surface and to increase with height in the atmospheric boundary layer. Wind speed is the most important aspect of the wind resource; in fact the year variation of long-term mean wind speed provides an understanding of the long-tern pattern of wind speed and also gives confidence to an investor in the availability of wind power in coming years [12].

The wind speed measured at weather station differs from the height of WTG hub. If these heights do not match the hub height of a WTG, it is necessary to extrapolate the wind speeds to the hub height of the WTG. This variation of wind speed with elevation is called the vertical profile of the wind speed or vertical wind shear, and it can be implemented by the following [13]:

$$
V_{Z}=V_{Z_{0}}\left(\frac{Z}{Z_{0}}\right)^{\alpha},
$$

where $V_{Z}$ is wind speed at the hub height of WTG; $V_{Z_{0}}$ is wind speed at the weather station; $Z$ is hub height of WTG; $Z_{0}$ is sea level height of the weather station; $\alpha$ is wind speed power law coefficient.

The actual wind power output of WTG is determined by the turbine performance curve, which is well described by (2). The $a_{1}-a_{4}$ coefficients of the power curve can be described by the specification of wind turbine manufacturer. The power curve with third-order equation is easily digitized into any discrete points dependent on the simulation accuracy. Consider

$$
P_{T}(V)= \begin{cases}0, & V \leq V_{i} \\ \left(a_{1} V^{3}+a_{2} V^{2}+a_{3} V+a_{4}\right) P_{r}, & V_{i} \leq V<V_{r} \\ P_{r}, & V_{r} \leq V<V_{r} \\ 0, & V \geq V_{f},\end{cases}
$$

where $a_{1}, a_{2}, a_{3}$, and $a_{4}$ are coefficients of the power curve of WTG; $V_{i}$ is cut-in speed of WTG; $V_{r}$ is rate speed of WTG; $V_{f}$ is cut-off speed of WTG; $P_{r}$ is rated power of WTG $(\mathrm{kW})$; $P_{T}(V)$ is the electrical power output of WTG $(\mathrm{kW})$.

After comparing the actual WTG energy output and the energy output with rated capacity, the capacity factor (CF) can be conducted. Consider

$$
\begin{aligned}
\mathrm{CF}=\frac{E_{\mathrm{TA}}}{E_{\mathrm{TR}}}= & \int_{V_{i}}^{V_{r}}\left(a_{1} V^{3}+a_{2} V^{2}+a_{3} V+a_{4}\right) f(V) d(V) \\
& +\int_{V_{r}}^{V_{f}} f(V) d(V) .
\end{aligned}
$$

The wind energy output from a wind turbine evaluated by the Weibull, Rayleigh, Lognormal, and Gamma probability models are denoted by the following:

$$
\begin{aligned}
& E_{\mathrm{TA}}=T \int_{V_{i}}^{V_{f}} P(V) f(V) d V \\
& =T P_{r} \int_{V_{i}}^{V_{r}}\left(a_{1} V^{3}+a_{2} V^{2}+a_{3} V+a_{4}\right)\left(\frac{k}{c}\right)\left(\frac{V}{c}\right)^{k-1} \\
& \times \exp \left[-\left(\frac{V}{c}\right)^{k}\right] d V \\
& +T P_{r} \int_{V_{r}}^{V_{f}}\left(\frac{k}{c}\right)\left(\frac{V}{c}\right)^{k-1} \exp \left[-\left(\frac{V}{c}\right)^{k}\right] d V \\
& E_{\mathrm{TA}}=T \int_{V_{i}}^{V_{f}} P(V) f(V) d V \\
& =T P_{r} \int_{V_{i}}^{V_{r}}\left(a_{1} V^{3}+a_{2} V^{2}+a_{3} V+a_{4}\right)\left(\frac{\pi}{2}\right)\left(\frac{V}{V_{m}^{2}}\right) \\
& \times \exp \left[-\left(\frac{\pi}{4}\right)\left(\frac{V}{V_{m}}\right)^{2}\right] d V \\
& +T P_{r} \int_{V_{r}}^{V_{f}}\left(\frac{\pi}{2}\right)\left(\frac{V}{V_{m}^{2}}\right) \exp \left[-\left(\frac{\pi}{4}\right)\left(\frac{V}{V_{m}}\right)^{2}\right] d V \\
& E_{\mathrm{TA}}=T \int_{V_{i}}^{V_{f}} P(V) f(V) d V \\
& =T P_{r} \int_{V_{i}}^{V_{r}}\left(a_{1} V^{3}+a_{2} V^{2}+a_{3} V+a_{4}\right) \frac{1}{\sigma \sqrt{2 \pi}} \\
& \times \exp \left[-\left(\frac{\left(V-V_{m}\right)^{2}}{2 \sigma^{2}}\right)\right] d V \\
& +T P_{r} \int_{V_{r}}^{V_{f}} \frac{1}{\sigma \sqrt{2 \pi}} \exp \left[-\left(\frac{\left(V-V_{m}\right)^{2}}{2 \sigma^{2}}\right)\right] d V \\
& E_{\mathrm{TA}}=T \int_{V_{i}}^{V_{f}} P(V) f(V) d V \\
& =T P_{r} \int_{V_{i}}^{V_{r}}\left(a_{1} V^{3}+a_{2} V^{2}+a_{3} V+a_{4}\right) \\
& \times\left[V^{k-1} \frac{\exp (-V / c)}{\Gamma(k) c^{k}}\right] d V \\
& +T P_{r} \int_{V_{r}}^{V_{f}}\left[V^{k-1} \frac{\exp (-V / c)}{\Gamma(k) c^{k}}\right] d V
\end{aligned}
$$

where $E_{\mathrm{TA}}$ is the actual wind energy output of the WTG for the period $T(\mathrm{~kW} / \mathrm{h}), E_{\mathrm{TR}}$ is the wind energy output operated with the full capacity for the period $T(\mathrm{~kW} / \mathrm{h}), f(V)$ is the probability density function (Weibull, Rayleigh, Lognormal, and Gamma), and $V_{m}$ is the mean winds speed $(\mathrm{m} / \mathrm{s})$. 


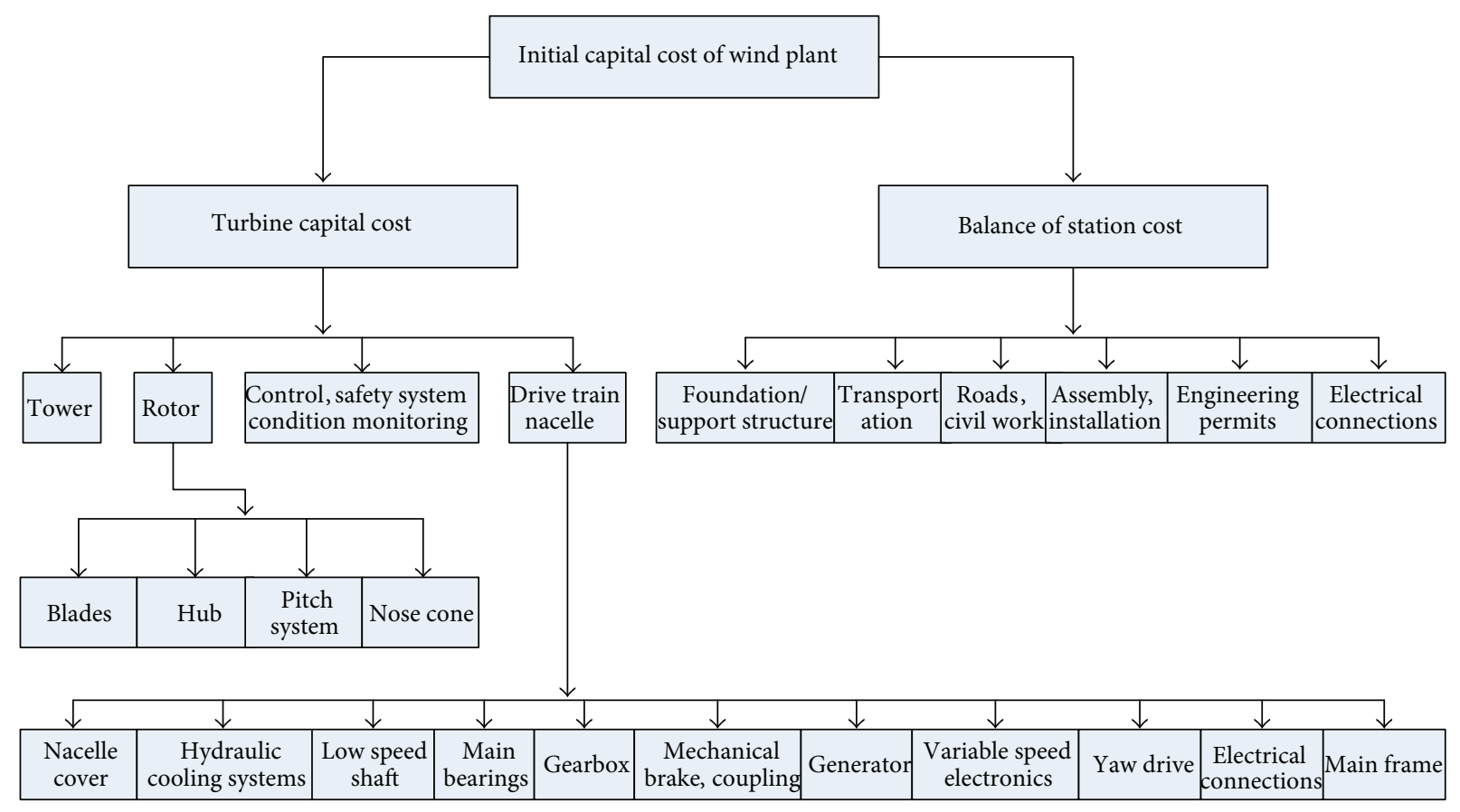

FIGURE 1: Initial capital cost model.

\section{Economic Analysis Methods}

The unit cost of wind electricity power can be determined by knowing capital investment and operating costs. It is important for estimating the investment cost of each WTG type in each location before installation. However, the value of the wind electricity power is somewhat difficult to determine, but it must be evaluated before making investment decision. The significant cost of wind energy will be included and discussed in this study.

The cost of energy (COE, $\$ / \mathrm{kWh}$ ) can be defined by (5), where $C_{\mathrm{TA}}$ is the total annual cost $(\$)$ and $E_{\mathrm{AP}}$ is the annual electrical energy output of WTG (kWh). Consider

$$
\mathrm{COE}=\frac{C_{\mathrm{TA}}}{E_{\mathrm{AP}}} .
$$

The total annual cost of a WTG is the sum of its operation, maintenance expenses, and annual repayments on its capital. It can be determined by the following:

$$
\begin{aligned}
C_{\mathrm{TA}} & =(a+0.025) \cdot C_{\mathrm{IT}} \\
a & =\frac{r}{1-(1+r)^{-t}},
\end{aligned}
$$

where $a$ is the discount factor; $r$ is the discount rate (\%) and often takes about $10 \%$; $t$ is the lifetime of project, often taken to be 20 years; $C_{\mathrm{IT}}$ is the initial capital cost of building WTG (\$).

The operation and maintenance cost yearly may be expressed as a proportion of the initial capital cost about $2.5 \%$ [14]. In this study, the initial capital cost of WTG is set based on references [10]. Using the model, the total annual cost
$\left(C_{\mathrm{TA}}\right)$ of the project can be estimated. The annual COE is a popular index to estimate the different amount of electricity for each WTG at each year. The component cost models needed to calculate the initial capital cost of wind turbine can be summarized in the following list of the components cost and in Figure 1 [11].

\section{List of the Components Cost}

$$
\begin{aligned}
& \text { Cost }_{\text {blade }}=0.5582\left(D_{r} / 2\right)^{2}+3.8118\left(D_{r} / 2\right)^{2.5025}- \\
& 955.24, \\
& \text { Mass }_{\text {blade }}=0.1452\left(D_{r} / 2\right)^{2.9158}, \\
& \text { Cost }_{\text {hub }}=4.05 \mathrm{Mass}_{\text {blade }}+24141, \\
& \text { Cost }_{\text {total-pith-system }}=0.4802 D_{r}^{2.6578}, \\
& \text { Cost }_{\text {nosecone }}=103 D_{r}-2899, \\
& \text { Cost }_{\text {low-speed-shaft }}=0.1 D_{r}^{2.887}, \\
& \text { Cost }_{\text {bearing-system }}=D_{r}^{2.5}\left(0.0043 D_{r}-0.011\right), \\
& \text { Cost }_{\text {gearbox }}=16.45 P_{r}^{1.249}, \\
& \text { Cost }_{\text {brake-coupling }}=1.9894 P_{r}-0.1144, \\
& \text { Cost }_{\text {generator }}=65 P_{r}, \\
& \text { Cost }_{\text {electronics }}=79 P_{r}, \\
& \text { Cost }_{\text {yaw-system }}=0.0678 D_{r}^{2.964}, \\
& \text { Cost }_{\text {main-frame }}=9.489 D_{r}^{1.953}, \\
& \text { Mass }_{\text {main-frame }}=2.233 D_{r}^{1.953}, \\
& \text { Cost }_{\text {platform-and-railing }}=1.09 \mathrm{Mass} \text { main-frame, } \\
& \text { Cost }_{\text {electrical-conection }}=40 P_{r}, \\
& \text { Cost }_{\text {hydraulic-and-cooling }}=12 P_{r},
\end{aligned}
$$




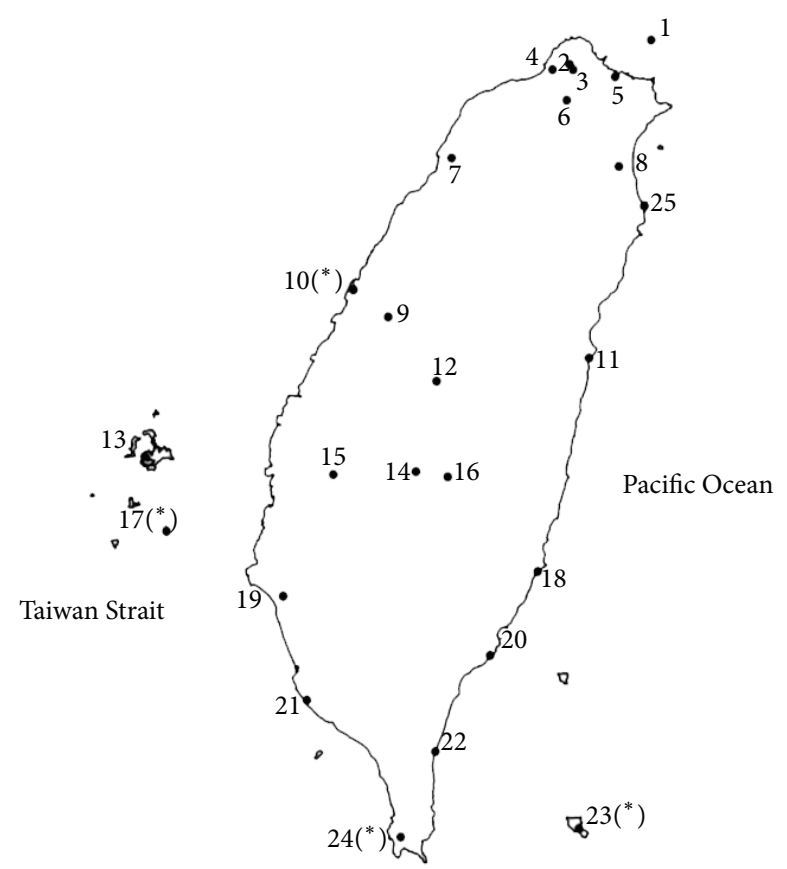

FIGURE 2: Geographical location of the meteorological stations used in the study.

$$
\begin{aligned}
& \text { Cost }_{\text {nacelle-cover }}=11.537 P_{r}+3849.7, \\
& \text { Cost }_{\text {control-safely-monitoring }}=\$ 35000, \\
& \text { Cost }_{\text {tower }}=0.596 \times A \times \mathrm{Hub}-2121, \\
& \text { Cost }_{\text {foundation }}=303.24 \times(A \times \mathrm{Hub})^{0.4037}, \\
& \text { Cost }_{\text {transportation }}=(1.58 E-5) P_{r}^{3}-0.0375 P_{r}^{2}+54.7 P_{r}, \\
& \text { Cost }_{\text {roads-civil-work }}=(2.17 E-6) P_{r}^{3}-0.0145 P_{r}^{2}+69.54 P_{r}, \\
& \text { Cost }_{\text {assembly-and-installation }}=1.965\left(\mathrm{Hub} \times D_{r}\right)^{1.1736}, \\
& \text { Cost }_{\text {electrical-interface }}=(3.49 E-6) P_{r}^{3}-0.0221 P_{r}^{2}+ \\
& 109.7 P_{r}, \\
& \text { Cost }_{\text {engineering-permiting }}=(9.94 E-4) P_{r}^{2}+20.31 P_{r} .
\end{aligned}
$$

In the above list, $D_{r}$ represents rotor radius $(\mathrm{m}), P_{r}$ is power nominal of wind turbine $(\mathrm{kW}), A$ is rotor swept area $\left(\mathrm{m}^{2}\right)$, and Hub is height of tower $(\mathrm{m})$.

\section{Simulation Results and Discussions}

In this study, the wind speed data were measured hourly by Central Weather Bureau of Taiwan in these six years at the 24 locations. All measurements in the wind observation station are recorded using the cup anemometer at a height of $10 \mathrm{~m}$ above the ground level. The geographical and meteorological information of the 24 stations is given in Figure 2 [1] and Table 1, respectively.

4.1. Simulation Results of Capacity Factor. The average power output and capacity factor of a WTG are very important parameters to show the performance of WTG. The related specifications of 20 popular commercial WTGs for testing are shown in Table 2 [13]. In general, the capacity factor decreases when the cut-in wind speed of a WTG reduces and its cut-off wind speed increases; another significant factor is the hub height of a WTG. The best and worst capacity factors at 24 tested sites evaluated by four different PDFs are listed in Table 3.

The highest CFs were operated by V90_1800 WTG at the $105 \mathrm{~m}$ hub height and E82 WTG at the height of $138 \mathrm{~m}$. The lowest CF was operated by the E44 WTG at the height of $44 \mathrm{~m}$. From the results of Table 3, three groups with different CF can be set.

(i) The First Group with High CF Regions. The CF varies from 0.482 to 0.6192 (with highest extreme status) and from 0.3111 to 0.4598 (with lowest extreme status); it includes the sites of Tungchitao, Lanyu, Yushan, and Pengchiayu. The highest CF occurs at Tungchitao with E82 WTG. The perfect CF operates at the sites of Lanyu and Pengchiayu by the V90_1800 WTG.

(ii) The Second Group with Average CF Regions. The CF varies from 0.045 to 2.587 (with highest extreme status) and from 0.0038 to 0.1336 (with lowest extreme status); it includes the sites of Wuchi, Hengchun, Penghu, Cheng Kung, Anpu, Keelung, Taipei, and Tainan. The average wind speed of this group varies in a range of $3 \mathrm{~m} / \mathrm{s} \sim 5 \mathrm{~m} / \mathrm{s}$, and the best CF in this group operated by E82 WTG with $138 \mathrm{~m}$ height occurs at Wuchi site. The worst CF calculated from whole probability density operated by E44 WTG with $45 \mathrm{~m}$ height occurs at Anpu site.

(iii) The Third Group of Small CF Regions. The remaining sites are Chutzehu, Tanshui, Hsinchu, Ilan, Taichung, Hualien, and so forth. The CF of WTG in this group is very low, while the lowest CF (with highest extreme status) occurs at Sun Moon Lake (0.0335) and Alishan (0.0243). The best capacity factor is operated by E82 WTG and the worst is operated by G80 WTG.

In general, the CF evaluated by the Weibull probability density in most of the sites is higher than that evaluated by other probability distributions, while the CF calculation by the lognormal model derived the lowest value.

4.2. Simulation Results of Wind Energy Cost. The capital cost of wind turbine depends on the size of wind turbine and its hub height. This study analyzes the sensitivity of minimizing cost of energy (COE) and specific rotor rating on various parameters and wind resource characteristics. The important decision is the choices of COE. As mentioned above, the wind energy resources of CF in Taiwan can be classified into three groups. The study of COE is focused on the first group with the higher wind energy potentials. Table 4 shows the evaluation of Pengchiayu site. In general, the wind speed at the first group, which includes Pengchiayu, Yushan, Tungchitao, and Lanyu, is very high; the wind speed at the weather stations' height is over $5.9 \mathrm{~m} / \mathrm{s}$. Therefore, the average capacity factors of wind turbines in this group are high. The maximum wind energy can be found in V90-3M wind turbine with $105 \mathrm{~m}$ hub height and the minimum can be found in E33 wind turbine with $36 \mathrm{~m}$ hub height. 
TABLE 1: Details of the geographical information for the tested weather stations.

\begin{tabular}{|c|c|c|c|c|}
\hline Number & Sites & Longitude (deg) & Latitude (deg) & Altitude $(\mathrm{m})$ \\
\hline 1 & Pengchiayu & $122^{\circ} 04^{\prime} \mathrm{E}$ & $25^{\circ} 37^{\prime} \mathrm{N}$ & 12.5 \\
\hline 2 & Anpu & $121^{\circ} 31^{\prime} \mathrm{E}$ & $25^{\circ} 11^{\prime} \mathrm{N}$ & 7.31 \\
\hline 3 & Chutzehu & $121^{\circ} 32^{\prime} \mathrm{E}$ & $25^{\circ} 09^{\prime} \mathrm{N}$ & 11.03 \\
\hline 4 & Tanshui & $121^{\circ} 26^{\prime} \mathrm{E}$ & $25^{\circ} 09^{\prime} \mathrm{N}$ & 12.2 \\
\hline 5 & Keelung & $121^{\circ} 43^{\prime} \mathrm{E}$ & $25^{\circ} 08^{\prime} \mathrm{N}$ & 34.6 \\
\hline 6 & Taipei & $121^{\circ} 30^{\prime} \mathrm{E}$ & $25^{\circ} 02^{\prime} \mathrm{N}$ & 34.9 \\
\hline 7 & Hsinchu & $120^{\circ} 58^{\prime} \mathrm{E}$ & $24^{\circ} 48^{\prime} \mathrm{N}$ & 15.6 \\
\hline 8 & Ilan & $121^{\circ} 44^{\prime} \mathrm{E}$ & $24^{\circ} 45^{\prime} \mathrm{N}$ & 26 \\
\hline 9 & Taichung & $120^{\circ} 40^{\prime} \mathrm{E}$ & $24^{\circ} 08^{\prime} \mathrm{N}$ & 17.2 \\
\hline 10 & Wuchi & $120^{\circ} 30^{\prime} \mathrm{E}$ & $24^{\circ} 15^{\prime} \mathrm{N}$ & 32.2 \\
\hline 11 & Hualien & $121^{\circ} 36^{\prime} \mathrm{E}$ & $23^{\circ} 58^{\prime} \mathrm{N}$ & 12 \\
\hline 12 & Sun Moon Lake & $120^{\circ} 53^{\prime} \mathrm{E}$ & $23^{\circ} 52^{\prime} \mathrm{N}$ & 8 \\
\hline 13 & Penghu & $119^{\circ} 33^{\prime} \mathrm{E}$ & $23^{\circ} 34^{\prime} \mathrm{N}$ & 14.6 \\
\hline 14 & Alishan & $120^{\circ} 48^{\prime} \mathrm{E}$ & $23^{\circ} 30^{\prime} \mathrm{N}$ & 15.1 \\
\hline 15 & Chiayi & $120^{\circ} 25^{\prime} \mathrm{E}$ & $23^{\circ} 29^{\prime} \mathrm{N}$ & 14.5 \\
\hline 16 & Yushan & $120^{\circ} 57^{\prime} \mathrm{E}$ & $23^{\circ} 29^{\prime} \mathrm{N}$ & 9.2 \\
\hline 17 & Tungchitao & $119^{\circ} 39^{\prime} \mathrm{E}$ & $23^{\circ} 15^{\prime} \mathrm{N}$ & 9.1 \\
\hline 18 & Cheng Kung & $121^{\circ} 21^{\prime} \mathrm{E}$ & $23^{\circ} 05^{\prime} \mathrm{N}$ & 12.8 \\
\hline 19 & Tainan & $120^{\circ} 11^{\prime} \mathrm{E}$ & $22^{\circ} 59^{\prime} \mathrm{N}$ & 37.6 \\
\hline 20 & Taitung & $121^{\circ} 08 \mathrm{E}$ & $22^{\circ} 45^{\prime} \mathrm{N}$ & 11.4 \\
\hline 21 & Kaohsiung & $120^{\circ} 18^{\prime} \mathrm{E}$ & $22^{\circ} 34^{\prime} \mathrm{N}$ & 14 \\
\hline 22 & Tawu & $120^{\circ} 53^{\prime} \mathrm{E}$ & $22^{\circ} 21^{\prime} \mathrm{N}$ & 12.7 \\
\hline 23 & Lanyu & $121^{\circ} 33^{\prime} \mathrm{E}$ & $22^{\circ} 02^{\prime} \mathrm{N}$ & 12.5 \\
\hline 24 & Hengchun & $120^{\circ} 44^{\prime} \mathrm{E}$ & $22^{\circ} 00^{\prime} \mathrm{N}$ & 14.3 \\
\hline
\end{tabular}

TABLE 2: Specifications of twenty different wind turbines.

\begin{tabular}{|c|c|c|c|c|c|c|c|}
\hline Number & WTG type & Rated power $(\mathrm{kW})$ & $\begin{array}{l}\text { Cut-in speed } \\
(\mathrm{m} / \mathrm{s})\end{array}$ & $\begin{array}{l}\text { Rated wind } \\
\text { speed }(\mathrm{m} / \mathrm{s})\end{array}$ & Cut-off speed (m/s) & $\begin{array}{l}\text { Rotor diameter } \\
(\mathrm{m})\end{array}$ & Hub height (m) \\
\hline 1 & E33 & 330 & 3 & 17 & $28-34$ & 33.4 & $36-50$ \\
\hline 2 & E44 & 900 & 2 & 17 & $28-34$ & 44 & $45-55$ \\
\hline 3 & $\mathrm{E} 48$ & 800 & 2 & 14 & $28-35$ & 48 & $50-76$ \\
\hline 4 & E53 & 800 & 2 & 13 & $28-36$ & 52.9 & $60 / 73$ \\
\hline 5 & E71 & 2300 & 2 & 15 & $28-37$ & 71 & $64-113$ \\
\hline 6 & E82 & 2000 & 2 & 12 & $28-38$ & 82 & $78-138$ \\
\hline 7 & G52 & 850 & 4 & 16 & 25 & 52 & $45 / 55 / 65$ \\
\hline 8 & G58 & 850 & 3 & 16 & 21 & 58 & $45 / 55 / 65$ \\
\hline 9 & G80 & 2000 & 4 & 17 & 25 & 80 & $44-71$ \\
\hline 10 & G87 & 2000 & 4 & 16 & 25 & 87 & $67-100$ \\
\hline 11 & G90 & 2000 & 3 & 16 & 21 & 90 & $67-100$ \\
\hline 12 & GE15xle & 1500 & 3.5 & 12.5 & 20 & 82.5 & 80 \\
\hline 13 & GE15sle & 1500 & 3.5 & 14 & 25 & 77 & $65 / 80$ \\
\hline 14 & GE25 & 2500 & 3.5 & 12.5 & 25 & 100 & $75 / 85 / 100$ \\
\hline 15 & V52 & 850 & 4 & 16 & 25 & 52 & $44 / 49 / 55 / 65 / 74$ \\
\hline 16 & V80 & 2000 & 4 & 15 & 25 & 80 & $60 / 67 / 78 / 100$ \\
\hline 17 & V82 & 1650 & 3.5 & 13 & 20 & 82 & $70 / 78 / 80$ \\
\hline 18 & V90_1.8 & 1800 & 3.5 & 12 & 25 & 90 & $80 / 95 / 105$ \\
\hline 19 & V90_2.0 & 2000 & 2.5 & 13 & $25 / 21$ & 90 & $80 / 95 / 106$ \\
\hline 20 & V90_3.0 & 3000 & 4 & 15 & 25 & 90 & $80 / 105$ \\
\hline
\end{tabular}




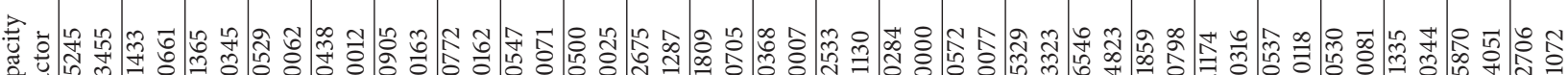

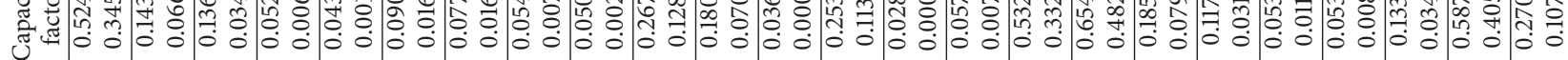

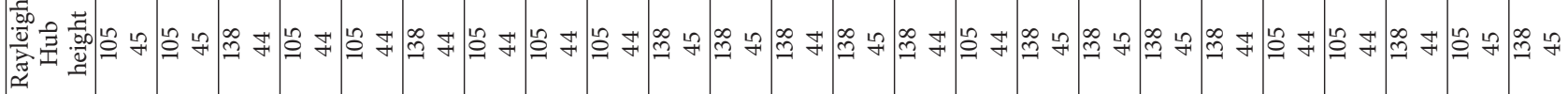

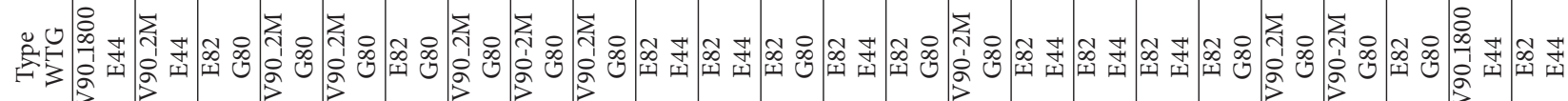

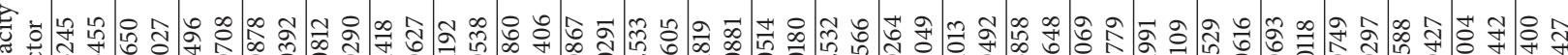

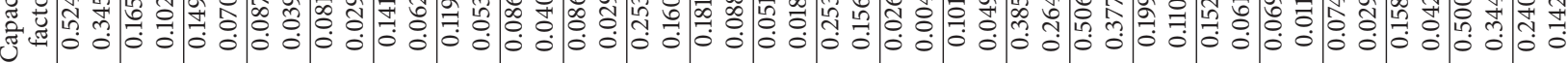

药

范

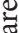

䒕

ลิ

:

要

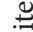

J

त

胥

㟧

产

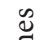

률

ज्ञ

茨

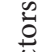

专

氙 :

$\ddot{n}$

焉

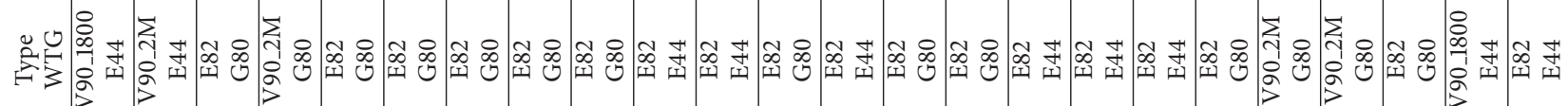

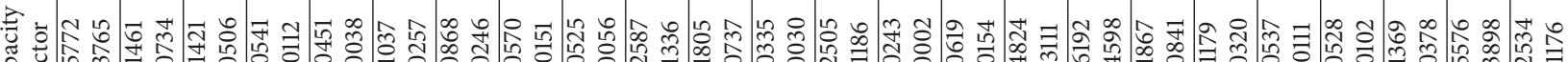

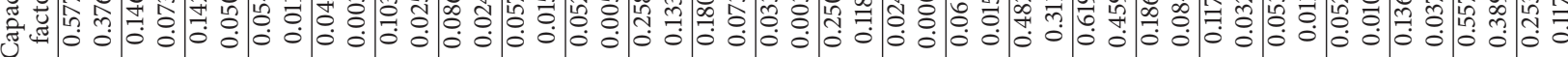

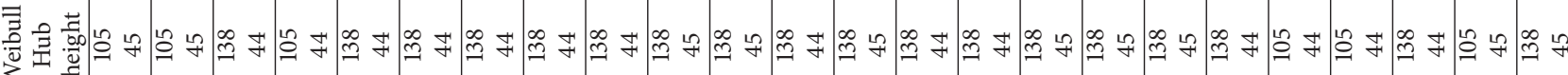

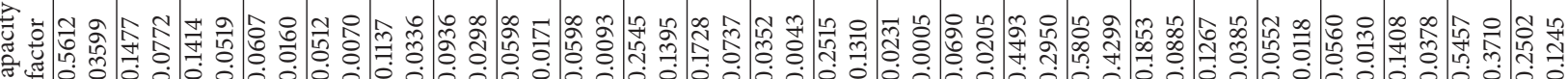

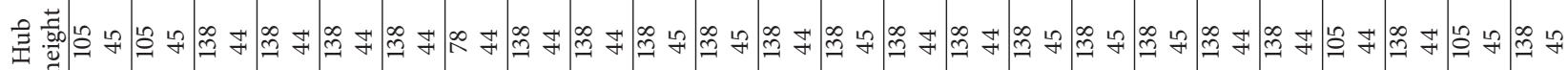

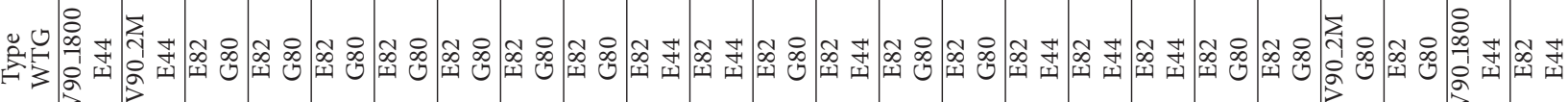

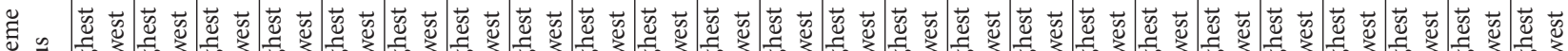

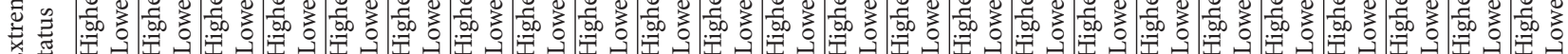
离

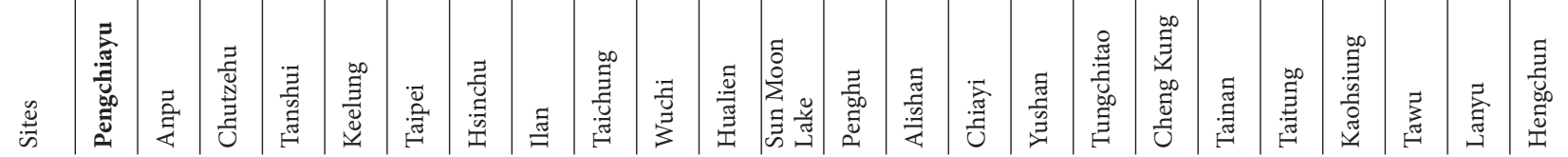




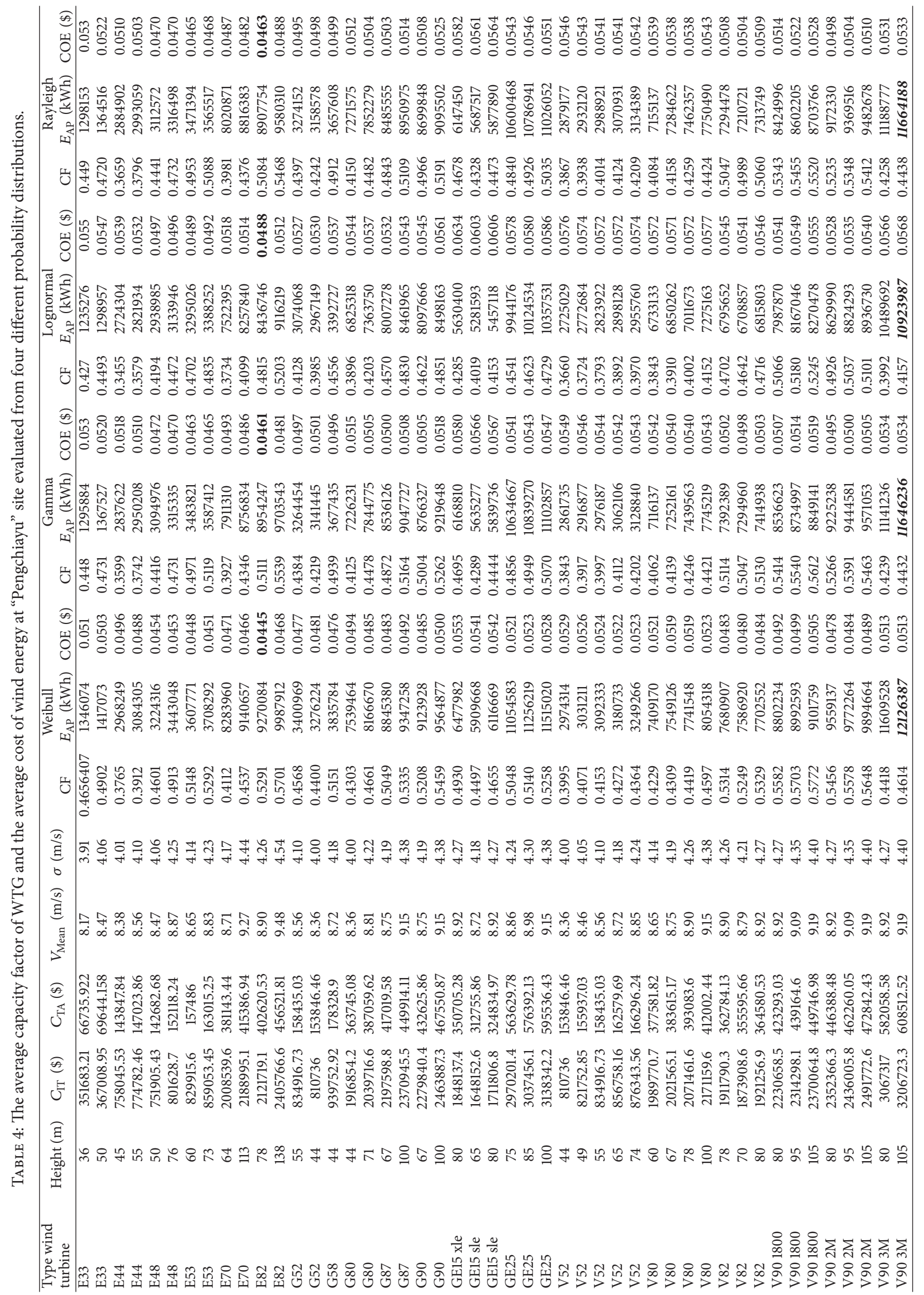


TABLE 5: The minimum COE at 24 sites within these six years.

\begin{tabular}{|c|c|c|c|c|c|c|c|c|c|}
\hline Sites & $F(v)$ & WTG & Hub height (m) & $\begin{array}{r}C_{\text {IT }} \\
(\$) \\
\end{array}$ & $\begin{array}{r}C_{\mathrm{TA}} \\
(\$) \\
\end{array}$ & $\begin{array}{l}V_{\text {mean }} \\
(\mathrm{m} / \mathrm{s})\end{array}$ & $\mathrm{CF}$ & $\begin{array}{c}E_{\mathrm{AP}} \\
(\mathrm{kWh})\end{array}$ & $\begin{array}{c}\mathrm{COE} \\
(\$ / \mathrm{kWh})\end{array}$ \\
\hline Pengchiayu & Weibull & E82 & 78 & 2121719.1 & 402620.5 & 8.898 & 0.529 & 9270084 & 0.0434 \\
\hline Anpu & Weibull & E82 & 138 & 2405766.6 & 456521.8 & 4.258 & 0.145 & 2553946 & 0.1788 \\
\hline Chutzehu & Weibull & E82 & 138 & 2405766.6 & 456521.8 & 3.937 & 0.142 & 2489782 & 0.1834 \\
\hline Tanshui & Weibull & E82 & 138 & 2405766.6 & 456521.8 & 2.796 & 0.053 & 940063 & 0.4856 \\
\hline Keelung & Weibull & E82 & 138 & 2405766.6 & 456521.8 & 2.525 & 0.045 & 789992 & 0.5779 \\
\hline Taipei & Reileigh & E82 & 138 & 2405766.6 & 456521.8 & 3.673 & 0.090 & 1585378 & 0.2880 \\
\hline Hsinchu & Weibull & E82 & 138 & 2405766.6 & 456521.8 & 3.390 & 0.086 & 1521036 & 0.3001 \\
\hline Ilan & Gamma & $\mathrm{E} 82$ & 138 & 2405766.6 & 456521.8 & 2.666 & 0.059 & 1047152 & 0.4360 \\
\hline Taichung & Weibull & E82 & 138 & 2405766.6 & 456521.8 & 2.780 & 0.052 & 920458 & 0.4960 \\
\hline Wuchi & Reileigh & E82 & 138 & 2405766.6 & 456521.8 & 5.726 & 0.267 & 468697 & 0.9740 \\
\hline Hualien & Gamma & E82 & 138 & 2405766.6 & 456521.8 & 4.868 & 0.172 & 3026950 & 0.1508 \\
\hline Sun Moon Lake & Gamma & E82 & 138 & 2405766.6 & 456521.8 & 2.067 & 0.035 & 616206 & 0.7409 \\
\hline Penghu & Reileigh & E82 & 138 & 2405766.6 & 456521.8 & 5.690 & 0.253 & 4438347 & 0.1029 \\
\hline Alishan & Gamma & E82 & 78 & 2121719.0 & 402620.5 & 1.475 & 0.021 & 367033 & 1.0970 \\
\hline Chiayi & Weibull & E82 & 138 & 2121719.0 & 456521.8 & 2.871 & 0.062 & 1083930 & 0.4212 \\
\hline Yushan & Reileigh & E82 & 78 & 2121719.0 & 402620.5 & 8.218 & 0.482 & 8443033 & 0.0477 \\
\hline Tungchitao & Weibull & $\mathrm{E} 48$ & 50 & 751905.40 & 142682.7 & 9.877 & 0.532 & 3728649 & 0.0383 \\
\hline Cheng Kung & Weibull & $\mathrm{E} 82$ & 138 & 2121719.0 & 456521.8 & 4.936 & 0.187 & 3270199 & 0.1396 \\
\hline Tainan & Gamma & E82 & 138 & 2121719.0 & 456521.8 & 4.270 & 0.127 & 2219498 & 0.2057 \\
\hline Taitung & Weibull & E82 & 138 & 2121719.0 & 456521.8 & 2.760 & 0.053 & 933972 & 0.4888 \\
\hline Kaohsiung & Gamma & V90 & 80 & 2352366.3 & 446388.5 & 2.677 & 0.050 & 878765 & 0.5080 \\
\hline Tawu & Weibull & E82 & 138 & 2405766.6 & 456521.8 & 4.375 & 0.137 & 2397660 & 0.1904 \\
\hline Lanyu & Reileigh & E82 & 78 & 2121719.1 & 402620.5 & 9.088 & 0.547 & 9579998 & 0.0420 \\
\hline Hengchun & Weibull & E82 & 138 & 2405766.6 & 456521.8 & 5.593 & 0.253 & 4439644 & 0.1028 \\
\hline
\end{tabular}

The average wind speeds shown in Table 4 in six years vary from $8.17 \mathrm{~m} / \mathrm{s}$ to $9.48 \mathrm{~m} / \mathrm{s}$. The minimum average wind speed can be found in E33 with a hub height of $36 \mathrm{~m}$, while the maximum can be found in E82 with a hub height of $138 \mathrm{~m}$. As a result, the CF of WTG and wind energy output is different when evaluated by different probability distributions. The maximum capacity factors computing from all probability functions can be found in V90-1800 at hub height of $105 \mathrm{~m}$, but the maximum wind energy output results from the V903M WTG at the same hub height. The minimum cost of wind energy cannot be found neither in V90-1800 nor in V90-3M but can be found in E82 WTG at hub height of $78 \mathrm{~m}$. From the simulation results, it can be concluded that the E82 WTG with $78 \mathrm{~m}$ hub height is the best option for installation at Pengchiayu site. It is noted that the average cost per $\mathrm{kWh}$ produced by all tested WTGs at Pengchiayu site during six years is below $0.06 \$ / \mathrm{kWh}$.

Of course, the designer can choose a proper PDF at each site to evaluate the wind energy of WTG and its minimum COE. However, the general comment is similar after analysis of the results of all 24 tested sites. The minimum COE at 24 sites within these six years is shown in Table 5. The Enercon WTG type E82 with lower cut-in wind speed and higher cut-off wind speed can be achieved by the best operational performance among all tested WTG. Lower COE result achieves smaller installation investment under the same wind energy output. The minimum COE $(0.0477 \$ / \mathrm{kWh})$ at Tungchitao site has the best performance, while Alishan site has the maximum COE (1.0970 \$/kWh).

\section{Conclusion}

In this study, the wind energy potential of 24 locations in Taiwan of six years was calculated. Great variations occur in the simulation results in both of the cost of energy $(0.03936 \sim 1.105 \$ / \mathrm{kWh})$ and capacity factor for different tested WTGs and 24 sites in Taiwan. Generally, capacity factor of the E82 GTW (at a height of $138 \mathrm{~m}$ ) was evaluated to achieve the best choice of WTG in Taiwan, but at some sites, the capacity factor of V90_1800 (the hub height is $105 \mathrm{~m}$ ) was second option. The capacity factor of WTG calculated from a Weibull probability distribution was higher than that calculated from other probability distributions, while the capacity factors of wind turbine computed by lognormal probability distribution was lower than those computed by other probability distributions. Any renewable energy system designer can benefit from the dedicated statistical analysis as investigated in this study to ensure the successful operation after WTG installations. 


\section{Conflict of Interests}

The authors declare that there is no conflict of interests regarding the publication of this paper.

\section{References}

[1] T.-J. Chang, Y.-T. Wu, H.-Y. Hsu, C.-R. Chu, and C.-M. Liao, "Assessment of wind characteristics and wind turbine characteristics in Taiwan," Renewable Energy, vol. 28, no. 6, pp. 851-871, 2003.

[2] A. Ucar and F. Balo, "Evaluation of wind energy potential and electricity generation at six locations in Turkey," Applied Energy, vol. 86, no. 10, pp. 1864-1872, 2009.

[3] A. Mostafaeipour, "Economic evaluation of small wind turbine utilization in Kerman, Iran," Energy Conversion and Management, vol. 73, pp. 214-225, 2013.

[4] K. Mohammadi and A. Mostafaeipour, "Economic feasibility of developing wind turbines in Aligoodarz, Iran," Energy Conversion and Management, vol. 76, pp. 645-653, 2013.

[5] S. L. Ferrell and E. A. DeVuyst, "Decommissioning wind energy projects: an economic and political analysis," Energy Policy, vol. 53, pp. 105-113, 2013.

[6] S. M. Shaahid, L. M. Al-Hadhrami, and M. K. Rahman, "Economic feasibility of development of wind power plants in coastal locations of Saudi Arabia-a review," Renewable and Sustainable Energy Reviews, vol. 19, pp. 589-597, 2013.

[7] R. Belu and D. Koracin, "Wind characteristics and wind energy potential in western Nevada," Renewable Energy, vol. 34, no. 10, pp. 2246-2251, 2009.

[8] F. Jowder, "Wind power analysis and site matching of wind turbine generators in Kingdom of Bahrain," Applied Energy, vol. 86, no. 4, pp. 538-545, 2009.

[9] M. Elamouri and F. Ben Amar, "Wind energy potential in Tunisia," Renewable Energy, vol. 33, no. 4, pp. 758-768, 2008.

[10] L. Fingersh, M. Hand, and A. Laxson, "Wind turbine design cost and scaling model," Tech. Rep. NREL/TP-500-40566, National Renewable Energy Laboratory, 2006.

[11] M. Schmidt, The economic optimization of wind turbine design [Master thesis], Georgia Institute of Technology, 2007.

[12] Y. Himri, S. Himri, and A. B. Stambouli, "Assessing the wind energy potential projects in Algeria," Renewable and Sustainable Energy Reviews, vol. 13, no. 8, pp. 2187-2191, 2009.

[13] I. Munteanu, A. I. Bratcu, and N. A. Cutululis, Optimal Control of Wind Energy Systems, Springer, 2008.

[14] T. Diveux, P. Sebastian, and J. R. Puiggali, "Horizontal axis wind turbine system: optimization using genetic algorithms," Wind Energy, vol. 4, pp. 151-171, 2001. 


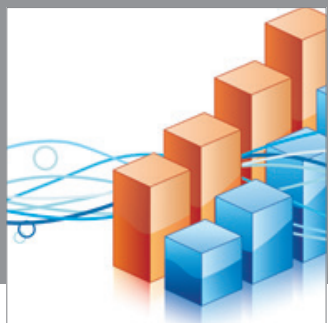

Advances in

Operations Research

mansans

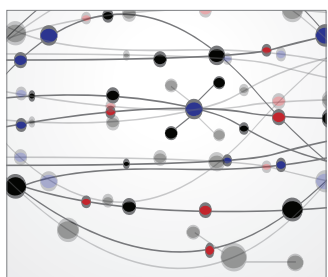

The Scientific World Journal
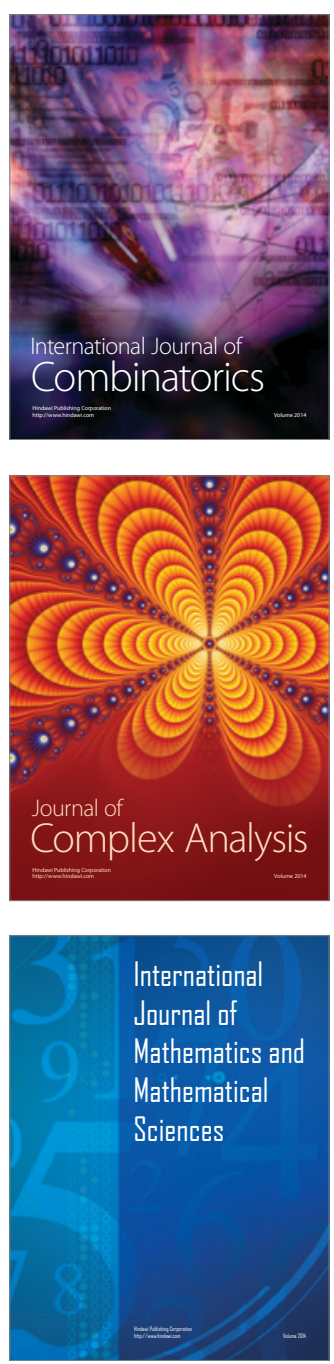
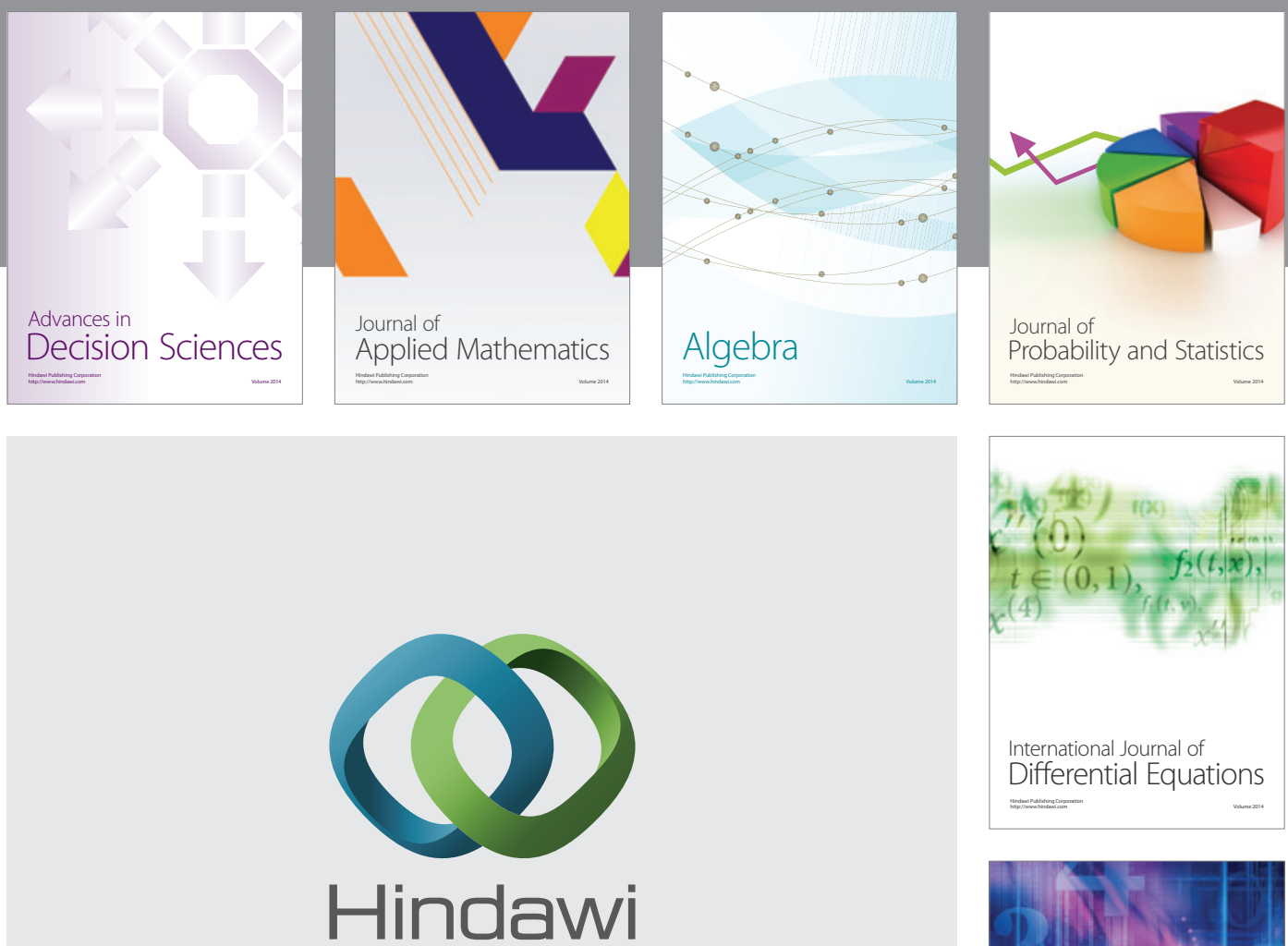

Submit your manuscripts at http://www.hindawi.com
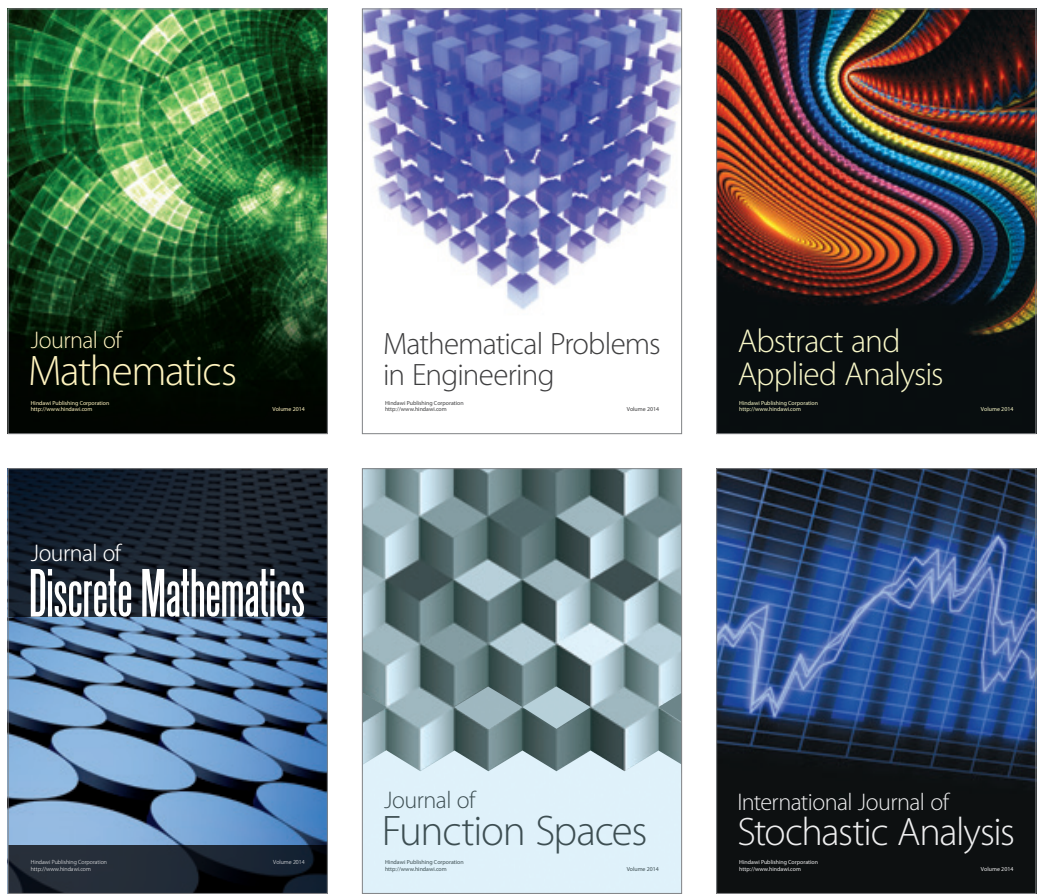

Journal of

Function Spaces

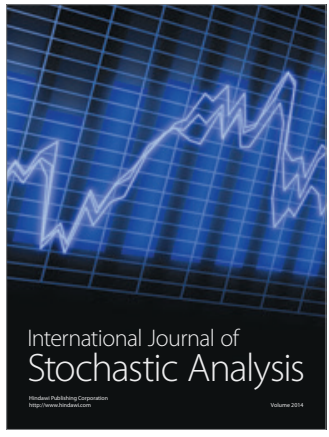

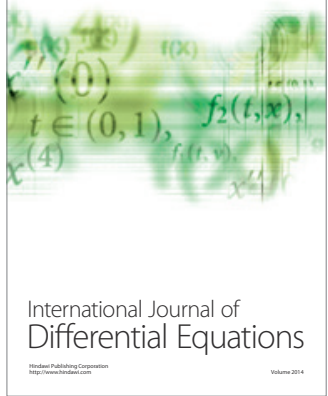
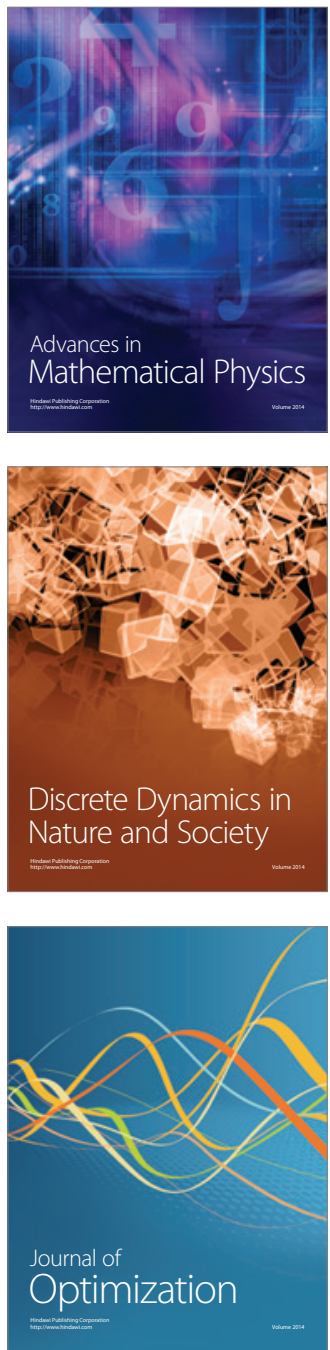